\title{
INTERFERÊNCIA ENTRE ESPÉCIES DE PLANTA DANINHA E DUAS CULTIVARES DE FEIJOEIRO EM DUAS ÉPOCAS DE SEMEADURA ( $\left.{ }^{1}\right)$
}

\author{
ARTHUR ARROBAS MARTINS BARROSO $\left({ }^{2 *}\right)$; MICHELI SATOMI YAMAUTI $\left({ }^{2}\right)$; \\ PEDRO LUIS DA COSTA AGUIAR ALVES $\left(^{(2)}\right.$
}

\begin{abstract}
RESUMO
O Brasil é o maior produtor mundial de feijão, mas a interferência das plantas daninhas pode causar reduções de produtividade entre $15 \%$ e $80 \%$, devido a fatores como cultivar de feijoeiro e espécies de plantas daninhas presentes na área. Objetivou-se com este trabalho avaliar os efeitos de seis espécies de plantas daninhas sobre o crescimento e a produtividade de duas cultivares de feijoeiro, em duas safras. Observou-se que as plantas eudicotiledôneas causam maior interferência na cultura, principalmente Amaranthus viridis e Raphanus raphanistrum. Todas causam perdas na produção do feijoeiro, exceto Eleusine indica, a menos competitiva. A cultivar 'Rubi' é mais produtiva e mais competitiva que a 'Carioca', e a maior produtividade é atingida na safra da seca. A escolha da cultivar e da data correta para a semeadura podem ser estratégias de manejo no controle de invasoras.
\end{abstract}

Palavras-chave: competição, Phaseolus vulgaris, plantas infestantes, Amaranthus viridis, Raphanus raphanistrum.

\section{ABSTRACT \\ INTERFERENCE BETWEEN WEED SPECIES AND TWO BEAN CULTIVARS IN TWO TIMES OF SOWING}

Brazil is the world's largest producer of bean, but weed interference can cause yield losses between 15 to $80 \%$ due several factors such as bean cultivar and weed species in the area. The objective of this study was to evaluate the effects of six weed species on growth and productivity of two bean cultivars, in two sowing seasons. It was observed that the dicot plants cause more interference in the crop, especially Amaranthus viridis and Raphanus raphanistrum. All cause losses in bean yield except Eleusine indica that was less competitive. The 'Rubi' bean cultivar is more productive and competitive than 'Carioca', and the higher production is achieved during the drought sowing season. The choice of cultivar and correct season for sowing may be management strategy as in weeds control.

Key words: competition, Phaseolus vulgaris, weeds, Amaranthus viridis, Raphanus raphanistrum.

(1) Recebido para publicação em 11 de setembro de 2009 e aceito em 10 de fevereiro de 2010.

(2) Departamento de Biologia Aplicada à Agropecuária, Universidade Estadual Paulista (UNESP), Via de Acesso Prof. Paulo Donato Castellane, s/n, 14884-900 Jaboticabal (SP). Brasil. E-mail: arthuragro07@hotmail.com. (*) Autor correspondente. 


\section{INTRODUÇÃO}

O feijão é uma das culturas mais importantes do Brasil, a terceira em área plantada, atingindo 9\% da área cultivada. O País é o maior produtor mundial de feijão, com 3,2 milhões de toneladas (CONAB, 2008). A produtividade média brasileira é de aproximadamente $882 \mathrm{~kg} \mathrm{ha}^{-1}$, muito baixa, considerando a possibilidade de se obter média de $3.483 \mathrm{~kg} \mathrm{ha}^{-1}$ (STONE, 2008). Esse fato ocorre porque há influência de vários fatores, dentre os quais a interferência das plantas daninhas (TeIXEIRA et al., 2009), que pode causar reduções de $15 \%$ a $80 \%$ na produtividade de grãos (SALGADO et al., 2007; KozLOWSKI et al., 2002). Redução de rendimento do feijoeiro em razão da interferência das plantas daninhas também foi verificada em outros países (NEARY e MAJEC, 1990). Em média, $20 \%$ a $30 \%$ do custo total de produção da cultura do feijoeiro se referem ao controle de plantas daninhas (SILVA et al., 2000).

O termo interferência refere-se ao conjunto de pressões ambientais que recebe uma determinada cultura agrícola em decorrência da presença das plantas infestantes no agroecossistema (RAmos e PITELLI, 1994). A interferência pode ser direta (competindo pelos recursos do crescimento, alelopatia e parasitismo, interferência na colheita e tratos culturais) e indireta (hospedando pragas, doenças e nematoides, infestando os produtos colhidos) (CARvalho e Velini, 2001). No primeiro caso, a disponibilidade de nutrientes assume grande importância no que se refere à perda de produção das culturas agrícolas (BlacKSHAW et al., 2003). ProcóPIO et al. (2004), por exemplo, verificaram que a adubação nitrogenada favoreceu mais o crescimento das plantas daninhas não Leguminosas, do que a cultura do feijoeiro, justificando a necessidade de manejo adequado.

Dentre os fatores condicionantes do grau de interferência, ainda se destacam as espécies presentes, levando-se em conta vigor, velocidade de crescimento inicial e densidade das plantas daninhas (SILVA et al., 2000), o suporte do ambiente (MAluf, 1999) e a cultivar. Neste caso, devem-se levar em conta os limites populacionais da cultura, para que não ocorra competição intraespecífica (SouZA, 2002).

Outro fator condicionante do grau de interferência é o período de convivência cultura-planta daninha. No período crítico de interferência das plantas daninhas com o feijoeiro há influência das condições ambientais, com variações de local para local e pode situar-se entre 15 e 57 dias após a emergência das plantas (KozLowsKi et al., 2002; SALGADO et al., 2007).

Com relação às espécies infestantes na cultura do feijão, o maior desafio concentra-se no manejo de eudicotiledôneas, tais como caruru (Amaranthus viridis), picão-preto (Bidens pilosa) e nabiça (Raphanus raphanistrum), seguido do manejo de algumas espécies perenes, como a tiririca, Cyperus rotundus (DEuber, 2007).

Em virtude do relatado, objetivou-se avaliar os efeitos de seis espécies de plantas daninhas (três monocotiledôneas e três eudicotiledôneas) sobre o crescimento e a produtividade das cultivares de feijoeiro 'Rubi' e 'Carioca', semeadas nas safras da seca e de inverno-primavera. Buscou-se, desta forma, conhecer a interferência das plantas em diversas épocas do ano e em diferentes cultivares de feijoeiro, a fim de contribuir para um manejo eficiente e acessível ao produtor.

\section{MATERIAL E MÉTODOS}

Foram desenvolvidos dois experimentos, em 2008, ambos sob condições semicontroladas, sem restrição de água, utilizando caixas de cimento amianto com capacidade para $50 \mathrm{~L}$ preenchidas com Latossolo Vermelho-Escuro e colocadas ao ar livre, sem proteção. Este substrato continha $\mathrm{pH}: 6,8 ; \mathrm{MO}: 37 \mathrm{~g} \mathrm{dm}^{-3} \mathrm{P}_{\text {(res. }_{\text {r }}}: 169$ $\mathrm{mg} \mathrm{dm}^{-3} ; \mathrm{K}, \mathrm{Ca}, \mathrm{Mg}, \mathrm{H}+\mathrm{Al}, \mathrm{SB}, \mathrm{T}$ e $\mathrm{V}(\%): 2,9 ; 87 ; 30 ; 20$; 119,$9 ; 139,9 \mathrm{mmol}_{\mathrm{c}} \mathrm{dm}^{-3}$ e $86 \%$ respectivamente; e teores de argila, silte, areia fina e areia grossa, respectivamente, de 480; 200; 140 e $180 \mathrm{~g} \mathrm{~kg}^{-1}$.

Para o feijoeiro, há pelo menos quatro épocas distintas de semeadura em função das condições climáticas, sendo o cultivo de verão outono (feijão da seca), com plantio em fevereiro-março e o cultivo de inverno-primavera, com semeadura em julho a início de agosto (PAUla Junior, 2007). Na tabela 1, estão relacionadas as condições climáticas que ocorreram durante o período dos experimentos.

As cultivares estudadas foram "Rubi" e "Carioca". A primeira tem alto potencial produtivo

Tabela 1. Temperatura média, umidade relativa do ar e precipitação pluvial mensal, durante o manejo dos experimentos. Jaboticabal, 2008

\begin{tabular}{|c|c|c|c|c|c|c|c|c|c|c|c|c|}
\hline Mês & Jan & Fev & Mar & Abr & Mai & Jun & Jul & Ago & Set & Out & Nov & Dez \\
\hline $\mathrm{T}$ média $\left({ }^{\circ} \mathrm{C}\right)$ & 23,5 & 23,9 & 23,2 & 22,3 & 19,1 & 19,4 & 19,1 & 21,8 & 21,8 & 24,6 & 24,3 & 23,9 \\
\hline UR (\%) & 83,7 & 81,9 & 79,1 & 82,3 & 74,7 & 74,3 & 57,7 & 58,4 & 59,6 & 68,3 & 71,4 & 77,0 \\
\hline Precipit. (mm) & 325,0 & 302,7 & 108,4 & 131,4 & 73,1 & 11,3 & 0,0 & 24,2 & 15,1 & 60,5 & 81,8 & 278,9 \\
\hline
\end{tabular}

Fonte: Dados da Estação Meteorológica da FCAV / UNESP. Jaboticabal, 2008. 
(3.900 $\left.\mathrm{kg} \mathrm{ha}^{-1}\right)$, grão do tipo carioca, porte prostrado e massa de mil sementes de $240 \mathrm{~g}$ (CARBOnELl et al., 2003). A cv. "Carioca", possui massa média de mil sementes de 200-250 g; porte prostrado, ciclo normal e resistência ao mosaico comum (EMBRAPA, 2009).

Estas cultivares foram semeadas em duas épocas, em março (seca) e agosto (inverno-primavera), depositando-se em linha, na porção mediana das caixas, seis sementes de feijão, reproduzindo-se a densidade de semeadura no campo, a qual possibilita maior produtividade (STONE, 2008).

Sementes de caruru-de-mancha (Amaranthus viridis - AMAVI), picão-preto (Bidens pilosa - BIDPI), nabiça (Raphanus raphanistrum - RAPRA), capimcolchão (Digitaria spp. - DIGSP) e pé-de-galinha (Eleusine indica - ELEIN) e tubérculos de tiririca (Cyperus rotundus - CYPRO) foram depositadas nas caixas, na mesma proporção e pareadas com as sementes de feijão, distanciadas de $10 \mathrm{~cm}$ entre si.

O delineamento experimental foi o de blocos casualizados, com três repetições e esquema fatorial $2 \times 7$, envolvendo as duas cultivares e sete tratamentos (seis espécies de plantas daninhas mais uma testemunha sem convivência para cada cultivar).

No decorrer do período experimental, em ambos os experimentos, foram feitas aplicações preventivas de inseticidas e fungicidas visando ao controle de mosca-branca (Bemisia tabaci), vaquinha-verdeamarela (Diabrotica speciosa) e ferrugem (Uromyces appendiculatus).

Por ocasião da colheita do feijão, foram determinados o número médio de vagens e a massa dos grãos por planta, estimando-se a produtividade de acordo com FANCELLI (2007). As plantas daninhas foram avaliadas quanto à altura e à massa seca da parte aérea.

Os dados foram submetidos à análise de variância. Nos casos de significância do teste $\mathrm{F}$, as médias foram comparadas pelo teste de Tukey, a 5\% de probabilidade.

\section{RESULTADOS E DISCUSSÃO}

A análise de variância dos dados relativos à altura e matéria seca de plantas daninhas revelou efeito significativo de espécies de planta daninhas sobre ambas as características, mas não houve efeito de cultivar de feijoeiro. A interação entre os fatores foi significativa apenas em relação à massa seca total na safra de invernoprimavera (Tabelas 2 e 3).

Na safra da seca, o desenvolvimento das plantas daninhas, principalmenteem termos dematériaseca total, foi menor em relação ao da safra de inverno-primavera. $\mathrm{Na}$ seca, as espécies que mais se desenvolveram foram caruru-de-mancha e nabiça, que acumularam as maiores biomassas no período de convivência (Tabela 2).

Tabela 2. Altura e massa seca total das plantas daninhas por ocasião da colheita do feijoeiro, em função de espécies de plantas daninhas e cultivares de feijoeiro em duas safras. Jaboticabal, 2008

\begin{tabular}{|c|c|c|c|c|c|c|c|c|}
\hline \multicolumn{9}{|c|}{ Plantas Daninhas (PD) } \\
\hline \multirow[b]{2}{*}{ Tratamentos } & \multicolumn{4}{|c|}{ Altura } & \multicolumn{4}{|c|}{ Massa seca total } \\
\hline & $\begin{array}{c}\text { Safra } \\
\text { da Seca }\end{array}$ & & \multicolumn{2}{|c|}{$\begin{array}{c}\text { Safra de } \\
\text { Inverno-Primavera }\end{array}$} & \multicolumn{2}{|c|}{$\begin{array}{c}\text { Safra } \\
\text { da Seca }\end{array}$} & \multicolumn{2}{|c|}{$\begin{array}{c}\text { Safra de } \\
\text { Inverno-Primavera }\end{array}$} \\
\hline Cyperus rotundus & 0,22 & $\mathrm{c}$ & 0,23 & $\bar{b}$ & 0.58 & $c$ & 2.15 & \\
\hline Amaranthus viridis & 0,85 & $\mathrm{a}$ & 0,69 & $\mathrm{a}$ & 8,79 & $a b$ & 37,18 & \\
\hline Digitaria spp. & 0,71 & a & 0,75 & $\mathrm{a}$ & 6,91 & $\mathrm{~b}$ & 25,61 & \\
\hline Raphanus raphanistrum & 0,75 & a & 0,69 & $\mathrm{a}$ & 12,59 & $\mathrm{a}$ & 14,28 & \\
\hline Eleusine indica & 0,43 & $\mathrm{~b}$ & 0,61 & $a b$ & 5,63 & $\mathrm{~b}$ & 24,78 & \\
\hline Bidens pilosa & 0,76 & $\mathrm{a}$ & 0,61 & $a b$ & 5,38 & $\mathrm{~b}$ & 2,52 & \\
\hline \multicolumn{9}{|c|}{ Cultivar (C) } \\
\hline 'Carioca' & 0,60 & $\mathrm{a}$ & 0,55 & $\mathrm{a}$ & 6,17 & $\mathrm{a}$ & 17,22 & \\
\hline 'Rubi' & 0,64 & $\mathrm{a}$ & 0,64 & $\mathrm{a}$ & 7,15 & $\mathrm{a}$ & 18,29 & \\
\hline F pd & 37,01 & *** & 4,08 & *** & 13,09 & ** & 23,33 & *** \\
\hline $\mathrm{Fc}$ & 1,71 & NS & 1,55 & NS & 1,17 & NS & 0,20 & NS \\
\hline F pdxc & 1,94 & NS & 0,22 & NS & 1,82 & NS & 4,16 & ** \\
\hline $\mathrm{dms} C$ & 0,06 & & 0,15 & & 1,85 & & 4,87 & \\
\hline dms PD & 0,17 & & 0,40 & & 4,80 & & 12,64 & \\
\hline $\mathrm{CV}(\%)$ & 15,76 & & 37,92 & & 40,43 & & 39,90 & \\
\hline
\end{tabular}

Dentro de safras, médias seguidas por letras diferentes na coluna diferem significativamente pelo teste Tukey a $5 \%$ de probabilidade. ${ }^{* *}$ Significativo ao nível de $1 \%$ de probabilidade pelo teste F. NS: Não significativo. 
Tabela 3. Efeito da interação entre os fatores sobre a massa seca total das plantas daninhas na safra de inverno-primavera. Jaboticabal, 2008

\begin{tabular}{|c|c|c|c|c|}
\hline \multirow{2}{*}{ Tratamentos } & \multicolumn{4}{|c|}{ Massa seca total } \\
\hline & \multicolumn{2}{|c|}{ 'Rubi' } & \multicolumn{2}{|c|}{ 'Carioca' } \\
\hline Cyperus rotundus & 2,09 & A c & 2,21 & $\mathrm{Ab}$ \\
\hline Amaranthus viridis & 47,94 & A a & 26,43 & $\mathrm{~B}$ a \\
\hline Digitaria spp. & 27,66 & $\mathrm{Ab}$ & 23,56 & A a \\
\hline Raphanus raphanistrum & 11,06 & $\mathrm{Abc}$ & 17,50 & $\mathrm{~A} a \mathrm{~b}$ \\
\hline Eleusine indica & 18,03 & $\mathrm{~B}$ bc & 31,53 & A a \\
\hline Bidens pilosa & 2,94 & $\mathrm{Ac}$ & 2,10 & $\mathrm{Ab}$ \\
\hline
\end{tabular}

Médias seguidas por diferentes letras diferentes diferem significativamente pelo teste Tukey a 5\% de probabilidade. Letras maiúsculas comparam cultivares e minúsculas, espécies de plantas daninhas.

Tabela 4. Efeito de espécies de plantas daninhas e de cultivares de feijoeiro sobre número de vagens por planta, massa de grãos por planta e produtividade estimada da leguminosa na safra da seca. Jaboticabal, 2008

\begin{tabular}{|c|c|c|c|c|c|c|}
\hline \multirow{2}{*}{ Tratamentos } & \multicolumn{6}{|c|}{ Plantas daninhas (PD) - Safra da Seca } \\
\hline & \multicolumn{2}{|c|}{ Vagens por planta } & \multicolumn{2}{|c|}{ Massa de grãos } & \multicolumn{2}{|c|}{ Produtividade estimada } \\
\hline & \multicolumn{2}{|c|}{$\mathrm{n} .^{\circ}$} & \multicolumn{2}{|c|}{$\mathrm{g}$} & \multicolumn{2}{|c|}{$\mathrm{kg} \mathrm{ha}^{-1}$} \\
\hline Cyperus rotundus & 7,55 & $a b$ & 50,73 & $\mathrm{ab}$ & $4.023,86$ & $\mathrm{~b}$ \\
\hline Amaranthus viridis & 7,78 & $a b$ & 49,40 & $\mathrm{~b}$ & $4.629,67$ & $\mathrm{~b}$ \\
\hline Digitaria spp. & 8,09 & $a b$ & 53,17 & $a b$ & $4.497,98$ & $a b$ \\
\hline Raphanus raphanistrum & 7,78 & $a b$ & 53,72 & $a b$ & $4.318,56$ & $\mathrm{~b}$ \\
\hline Eleusine indica & 7,65 & $a b$ & 51,51 & $a b$ & $4.549,27$ & $a b$ \\
\hline Bidens pilosa & 7,38 & $\mathrm{~b}$ & 36,31 & $\mathrm{~b}$ & $4.251,95$ & $\mathrm{~b}$ \\
\hline Testemunha & 9,09 & $\mathrm{a}$ & 69,31 & $\mathrm{a}$ & $6.038,90$ & $\mathrm{a}$ \\
\hline \multicolumn{7}{|c|}{ Cultivar (C) } \\
\hline 'Carioca' & 7,73 & $\mathrm{a}$ & 51,64 & $\mathrm{a}$ & $4.500,88$ & $\mathrm{a}$ \\
\hline 'Rubi' & 8,08 & $\mathrm{a}$ & 55,27 & $\mathrm{a}$ & $4.627,75$ & $\mathrm{a}$ \\
\hline F pd & 2,70 & * & 2,33 & NS & 3,56 & $* *$ \\
\hline $\mathrm{F} \mathrm{c}$ & 1,72 & NS & 0,98 & NS & 0,22 & NS \\
\hline F pdxc & 0,98 & NS & 1,68 & NS & 1,11 & NS \\
\hline $\mathrm{dms} C$ & 0,54 & & 7,53 & & 552,16 & \\
\hline dms PD & 1,55 & & 21,77 & & $1.597,60$ & \\
\hline $\mathrm{CV}(\%)$ & 10,69 & & 22,25 & & 19,12 & \\
\hline
\end{tabular}

Médias seguidas por diferentes letras diferentes na coluna diferem significativamente pelo teste Tukey a $5 \%$ de probabilidade. **Significativo ao nível de $1 \%$ de probabilidade pelo teste $\mathrm{F}$, NS Não significativo.

$\mathrm{Na}$ safra de inverno-primavera, apesar da interação significativa, as plantas de caruru proporcionaram maior massa seca total em ambas as cultivares. Nesta última época, as cultivares diferiram quanto à massa seca total de caruru e pé-de-galinha, mas foram equivalentes quanto à massa seca total das demais espécies de plantas daninhas (Tabela 3).

A análise de variância das características do feijoeiro indicou que na safra de inverno-primavera, as espécies de plantas daninhase as cultivares influenciaram significativamente o número de vagens por planta, a massa de grãos por planta e a produtividade, enquanto na da seca não houve efeito de cultivares e as espécies daninhas influenciaram o número de vagens por planta e a produtividade. A interação apenas foi significativa na safra de inverno-primavera, em relação à massa de grãos e produtividade (Tabelas 4 e 5).

$\mathrm{Na}$ seca, independentemente da cultivar, as convivências com capim-pé-de-galinha e capim-colchão não causaram reduções significativas na produtividade do feijoeiro. Na convivência com plantas de tiririca, caruru, nabiça e picão-preto ocorreu redução de $23,3 \%$ a $33,4 \%$ na produtividade (Tabela 4). A convivência com picão-preto causou redução no número de vagens por planta e na massa dos grãos produzidos, enquanto a convivência com caruru causou redução na massa 
Tabela 5. Efeito de espécies de plantas daninhas e de cultivares de feijoeiro sobre número de vagens por planta, massa de grãos por planta e produtividade estimada da leguminosa na safra de inverno-primavera. Jaboticabal, 2008

\begin{tabular}{|c|c|c|c|c|c|c|}
\hline \multirow{2}{*}{ Tratamentos } & \multicolumn{6}{|c|}{ Plantas Daninhas (PD) - Safra de Inverno-Primavera } \\
\hline & \multicolumn{2}{|c|}{ Vagens por planta } & \multicolumn{2}{|c|}{ Massa de grãos } & \multicolumn{2}{|c|}{ Produtividade estimada } \\
\hline & \multicolumn{2}{|c|}{ n..$^{\circ}$} & \multicolumn{2}{|c|}{$\mathrm{g}$} & \multicolumn{2}{|c|}{$\mathrm{kg} \mathrm{ha}^{-1}$} \\
\hline Cyperus rotundus & 5,27 & $\mathrm{~b}$ & 19,08 & & $2.243,32$ & \\
\hline Amaranthus viridis & 3,20 & c & 5,20 & & 648,62 & \\
\hline Digitaria spp. & 5,32 & $\mathrm{~b}$ & 17,64 & & $2.363,24$ & \\
\hline Raphanus raphanistrum & 5,61 & $a b$ & 25,54 & & $2.842,02$ & \\
\hline Eleusine indica & 5,64 & $a b$ & 22,10 & & $2.808,17$ & \\
\hline Bidens pilosa & 5,73 & $a b$ & 21,81 & & $2.832,80$ & \\
\hline Testemunha & 6,49 & $\mathrm{a}$ & 29,06 & & $3.688,41$ & \\
\hline \multicolumn{7}{|c|}{ Cultivar (C) } \\
\hline 'Carioca' & 4,80 & $\mathrm{~b}$ & 15,95 & & $1.933,81$ & \\
\hline 'Rubi' & 5,85 & $\mathrm{a}$ & 24,18 & & $3.045,21$ & \\
\hline F pd & 15,68 & *** & 14,24 & *** & 12,17 & $* *$ \\
\hline $\mathrm{F} \mathrm{c}$ & 29,21 & $* *$ & 29,29 & $* *$ & 30,08 & $* *$ \\
\hline F pdxc & 2,43 & NS & 2,92 & $*$ & 2,56 & $*$ \\
\hline $\mathrm{dms} C$ & 0,40 & & 3,12 & & 415,35 & \\
\hline dms PD & 1,15 & & 9,02 & & $1.201,76$ & \\
\hline $\mathrm{CV}(\%)$ & 11,84 & & 24,55 & & 26,37 & \\
\hline
\end{tabular}

Médias seguidas por diferentes letras diferentes na coluna diferem significativamente pelo teste Tukey a 5\% de probabilidade. .**ignificativo ao nível de $1 \%$ de probabilidade pelo teste F, Ns Não significativo.

Tabela 6. Efeito de espécies de plantas daninhas sobre a massa dos grãos por planta do feijoeiro, na safra de Inverno-Primavera. Jaboticabal, 2008

\begin{tabular}{|c|c|c|c|c|}
\hline \multirow{2}{*}{ Tratamentos } & \multicolumn{4}{|c|}{ Massa de grãos } \\
\hline & \multicolumn{2}{|c|}{ 'Rubi' } & \multicolumn{2}{|c|}{ 'Carioca' } \\
\hline Cyperus rotundus & 18,96 & $\mathrm{Ab}$ & 19,20 & $\mathrm{~A} a b$ \\
\hline Amaranthus viridis & 3,87 & $\mathrm{Ac}$ & 6,54 & $\mathrm{Ab}$ \\
\hline Digitaria spp. & 24,71 & $\mathrm{~A} a b$ & 10,57 & $\mathrm{~B} \mathrm{~b}$ \\
\hline Raphanus raphanistrum & 32,04 & $\mathrm{~A} \mathrm{a}$ & 19,04 & $\mathrm{~B}$ ab \\
\hline Eleusine indica & 27,99 & $\mathrm{~A} a b$ & 16,21 & $\mathrm{~B} a b$ \\
\hline Bidens pilosa & 28,33 & $\mathrm{~A} a b$ & 15,30 & $\mathrm{~B} a b$ \\
\hline Testemunha & 33,34 & $\mathrm{~A} \mathrm{a}$ & 24,78 & $\mathrm{~B}$ a \\
\hline
\end{tabular}

Médias seguidas por diferentes letras diferentes na coluna diferem significativamente pelo teste Tukey a 5\% de probabilidade. Letras maiúsculas comparam cultivares e minúsculas, espécies de plantas daninhas.

de grãos. A convivência com as demais espécies de plantas daninhas não afetou de modo significativo as características avaliadas na leguminosa na época da seca (Tabela 4).

Como pode ser observado na tabela 4, na seca não se constatou diferença entre as cultivares Rubi e Carioca quanto às características analisadas, independentemente da condição de convivência com as plantas daninhas.

$\mathrm{Na}$ safra de inverno-primavera, independentemente da cultivar, verificou-se que a convivência com plantas de caruru afetou o número de vagens por planta, revelando-se a mais prejudicial à cultura. As plantas de tiririca e de capim-colchão, cujos efeitos não diferiram entre si, causaram reduções intermediárias nesta característica (Tabela 5). Verificouse que a cultivar 'Rubi' produziu mais vagens por planta que a 'Carioca', independentemente da espécie de planta daninha com que conviveu.

Na safra de inverno-primavera, na convivência com a cv. 'Rubi', a menor e a maior redução na massa de grãos foram causadas por tiririca e caruru, respectivamente. Já para a 'Carioca', essa redução foi observada em igual nível pela convivência do feijão com plantas de caruru e capim-colchão (Tabela 6). Tiririca e caruru causaram semelhante efeito competitivo na 
Tabela 7. Efeito de espécies de plantas daninhas sobre a produtividade estimada de duas cultivares de feijoeiro na safra de Inverno-Primavera. Jaboticabal, 2008

\begin{tabular}{|c|c|c|c|c|}
\hline \multirow{2}{*}{ Tratamentos } & \multicolumn{4}{|c|}{ Produtividade estimada } \\
\hline & \multicolumn{2}{|l|}{ 'Rubi' } & \multicolumn{2}{|c|}{ 'Carioca' } \\
\hline & - & $-\mathrm{kg}$ & & - \\
\hline Cyperus rotundus & $2.305,81$ & $\mathrm{~A} a b$ & $2.180,82$ & $\mathrm{~A} a b$ \\
\hline Amaranthus viridis & 685,97 & $\mathrm{Ab}$ & 611,28 & $\mathrm{Ab}$ \\
\hline Digitaria spp. & $3.123,04$ & $\mathrm{~A} \mathrm{a}$ & $1.603,44$ & $\mathrm{~B} \mathrm{~b}$ \\
\hline Raphanus raphanistrum & $3.742,88$ & $\mathrm{~A}$ a & $1.941,13$ & $\mathrm{~B} \mathrm{ab}$ \\
\hline Eleusine indica & $3.823,89$ & $\mathrm{~A}$ a & $1.792,45$ & $\mathrm{~B} \mathrm{ab}$ \\
\hline Bidens pilosa & $3.719,46$ & $\mathrm{~A} \mathrm{a}$ & $1.946,13$ & $\mathrm{~B} a \mathrm{~b}$ \\
\hline Testemunha & $3.915,44$ & $\mathrm{~A} \mathrm{a}$ & $3.461,38$ & $\mathrm{~A} \mathrm{a}$ \\
\hline
\end{tabular}

Médias seguidas por diferentes letras diferentes na coluna diferem significativamente pelo teste Tukey a 5\% de probabilidade. Letras maiúsculas comparam cultivares e minúsculas, espécies de plantas daninhas.

safra de inverno-primavera, independentemente da cultivar de feijão com a qual conviveram. As plantas de capim-colchão, nabiça, capim-pé-de-galinha e picãopreto causaram maior competição quando conviveram com 'Carioca'. Constatou-se ainda que 'Rubi' produziu maior massa de grãos em relação a 'Carioca' (Tabela 5), o que pode resultar de maior eficiência desta cultivar em utilizar os nutrientes disponíveis no solo (Tabela 6). Estes resultados são semelhantes aos obtidos por VALÉRIO (1999).

Na safra de inverno-primavera, a convivência com as plantas de caruru causou redução média de $82 \%$ na produtividade de ambas as cultivares; já o capim-colchão reduziu a produtividade apenas da 'Carioca' (54\%), enquanto as demais espécies de plantas daninhas a tendência de redução foi na produtividade desta cultivar (Tabela 7). Analisando o efeito da espécie de planta daninha dentro das cultivares, verificouse que na cv. 'Carioca', a convivência com capimcolchão, nabiça, pé-de-galinha e picão-preto, produziu menos que na 'Rubi', enquanto sem a convivência com plantas daninhas, ou com a convivência com tiririca ou com caruru, a produtividade das duas cultivares foi equivalente.

Na safra de inverno-primavera, a massa seca total acumulada das plantas infestantes foi maior em relação à safra da seca (Tabela 2), com desenvolvimento maior das plantas devido a altas temperaturas, combinadas a um bom suprimento hídrico. Consequentemente, ocorreu maior interferência das plantas daninhas no feijoeiro, ocasionando menor produtividade da cultura nesta safra, assim como constatado por TEIXEIRA (2009).

Em ambas as safras, a planta mais agressiva foi o caruru-de-mancha (AMAVI), que interferiu no crescimento e na produção do feijoeiro nas duas épocas de semeadura. Trata-se de espécie que possui via de fixação de carbono do tipo $\mathrm{C}_{4^{\prime}}$ cujo hábito de crescimento agressivo promove alta competitividade por água, luz e nutrientes (Kissmann e GROTH, 1999). Este mecanismo fotossintético confere diversas vantagens em relação às plantas $C_{3}$, como o feijoeiro, principalmente em ambientes quentes e úmidos (PAUl e Elmore, 1984). Provavelmente, em decorrência deste fato, foi observada maior competição com o feijoeiro na safra de inverno-primavera, quando ocorreu maior acúmulo de matéria seca nesta planta daninha em relação às outras espécies.

A convivência com plantas de nabiça (RAPRA) foi prejudicial ao feijoeiro, mas dependente das condições edafoclimáticas, pelo fato de, na segunda época de semeadura, sob temperaturas mais elevadas (Tabela 1), não ter interferido na produtividade de ambas as cultivares de feijoeiro (Tabela 7). Segundo Kissmann e GROTH (1999), a competição exercida pelas plantas de nabiça sob temperaturas mais elevadas ocorre apenas durante o início do ciclo das culturas, tendo significância reduzida na produtividade final, ou seja, a planta exerceu poucos efeitos competitivos durante a formação de vagens no feijoeiro.

O picão-preto (BIDPI) foi menos competitivo na safra de inverno-primavera, na qual os feijoeiros tiveram desenvolvimento mais rápido e suprimiram seu crescimento. Mesmo assim, a interferência inicial da planta daninha acarretou prejuízos na produtividade da cultura na safra da seca (Tabela 2), pois, segundo SANTOS et al. (2008), Bidens pilosa é uma espécie com grande potencial para infestação devido à maior exploração do solo.

Cyperus rotundus (CYPRO), mesmo com pouco acúmulo de matéria seca, causou interferência na produtividade do feijoeiro, em ambas as épocas (Tabelas 4 e 7), e redução no número de vagens por planta e na massa dos grãos durante a safra da 
seca (Tabela 4), provavelmente devido ao fato de se propagar rapidamente por tubérculos e também por exsudar aleloquímicos (Muniz, 2007). Por ser uma espécie de rápido desenvolvimento em condições de alta luminosidade (SANTOS et al., 1997), durante a safra da seca, sua agressividade foi maior, devido ao desenvolvimento mais lento do feijoeiro, possibilitando assim melhor aproveitamento de luz pelas plantas daninhas.

As plantas de Digitaria spp. (DIGSP), por se desenvolverem preferencialmente em solos férteis, serem resistentes a condições de seca e possuírem efeitos alelopáticos sobre plantas cultivadas (KISSMANN e GROTH, 1999), na segunda época de semeadura tiveram grande desenvolvimento, pois a precipitação pluvial foi menor e as temperaturas mais elevadas (Tabela 1), ao ponto de prejudicar a produtividade do feijoeiro em $36 \%$.

O capim-pé-de-galinha (ELEIN) não teve a capacidade de interferir nos processos fisiológicos do feijoeiro de maneira que viesse causar perdas significativas na produtividade, em ambas as safras, embora apresente um sistema radicular bem desenvolvido (LORENZI, 2006).

Comparando as duas safras e as cultivares utilizadas, verificou-se que a produtividade estimada do feijoeiro foi maior quando cultivado na safra da seca $\left(4.627,75 \mathrm{~kg} \mathrm{ha}^{-1}\right)$, comparada à safra de invernoprimavera $\left(3.045,21 \mathrm{~kg} \mathrm{ha}^{-1}\right)$, e que a cultivar Rubi foi mais competitiva. RodRigues et al. (2002) também verificaram elevado rendimento de grãos decorrente das condições favoráveis de ambiente.

\section{CONCLUSÕES}

1. As plantas daninhas eudicotiledôneas afetam mais o desenvolvimento e a produtividade do feijoeiro do que as monocotiledôneas. As espécies mais competitivas são o caruru-de-mancha (Amaranthus viridis) e a nabiça (Raphanus raphanistrum).

2. A cultivar Rubi foi mais competitiva que a cv. Carioca; ambas proporcionaram maiores produções na safra da seca, quando o desenvolvimento das plantas daninhas foi menor.

3. A safra de inverno-primavera é mais propícia ao desenvolvimento de caruru-de-mancha (Amaranthus viridis), picão-preto (Bidens pilosa), nabiça (Raphanus raphanistrum), capim-colchão (Digitaria spp.), pé-degalinha (Eleusine indica) e tiririca (Cyperus rotundus).

4. A escolha da cultivar e da época de semeadura são estratégias simples que devem ser incluídas para o manejo eficiente de plantas daninhas na cultura do feijoeiro.

\section{AGRADECIMENTOS}

À FAPESP, pela concessão da bolsa de iniciação científica a A.A.M. Barroso, e ao $\mathrm{CNPq}$, pela concessão de bolsa PQ a P.L.C.A. Alves.

\section{REFERÊNCIAS}

BLACKSHAW, R.E. et al. Differential response of weed species to added nitrogen. Weed Science, v.51, p.532-539, 2003.

CARBONELL, S.A.M. et al. Cultivares comerciais de feijoeiro para o Estado de São Paulo: características e melhoramento. In: CASTRO, J.L.; ITO, M.F. (Coord.). DIA DE CAMPO DE FEIJÃO, 19., 2003, Capão Bonito. Anais... Campinas: IAC, 2003. p. 5-27.

CARVALHO, F.T.; VELINI, E.D. Períodos de interferência de plantas daninhas na cultura da soja. Planta Daninha, v.19, p.317-322, 2001.

COMPANHIANACIONALDOABASTECIMENTO-CONAB. Safra de feijão total $\left(1 .^{a},{ }^{2} .^{a}\right.$ e $3 .^{a}$ safras $)-3 .^{\circ}$ levantamento. Brasília. Disponível em: <http:www.conab.br >. Acesso em: 24 abr. 2008.

DEUBER, R. Desafios no controle de plantas daninhas em feijoeiro na Região Sudeste do Brasil. In: SEMINÁRIO SOBRE PRAGAS, DOENÇAS E PLANTAS DANINHAS DO FEIJOEIRO, 6., 2006, Campinas. Anais...Campinas: IAC, 2007.

EMBRAPA. Empresa Brasileira de Pesquisa Agropecuária. Cultivares. Disponível em: < http:/ / www.cnpaf.embrapa.br / feijao/perola.htm>. Acesso em 21 fev. 2009.

FANCELLI, A.L.; DOURADO-NETO, D. Produção de Feijão. Piracicaba: ESALQ/USP, Departamento de Agricultura, 2007. 46p.

KISSMANN, K.G.; GROTH, D. Plantas infestantes e nocivas. 2.ed. São Paulo: BASF, 1999. v.2, 978p.

KOZLOWSKI, L.A. et al. Interferência de plantas daninhas na cultura do feijoeiro comum em sistema de semeadura direta. Planta Daninha, v.20, p.213-220, 2002.

LORENZI, H.J. Manual de identificação e controle de plantas daninhas: plantio direto e convencional. 6.ed. Nova Odessa: Plantarum, 2006. 336p.

MALUF, A. M. Competição intraespecífica entre Amaranthus hybridus L. e Amaranthus viridis L.. Pesquisa Agropecuária Brasileira, v.34, p.1319-1325, 1999.

MUNIZ, F. R. et al. Qualidade fisiológica de sementes de milho, feijão, soja e alface na presença de extrato de tiririca. Revista Brasileira de Sementes, v.29, p.195-204, 2007.

NEARY, P.E.; MAJEK, B.A. Common cocklebur (Xanthium strumarium) interference in snap beans (Phaseolus vulgaris). Weed Technology, v.4, p.743-748, 1990. 
PAUL, R.; ELMORE, C.D. Weeds and the C4 syndrome. Weeds Today, v.15, p.3-4, 1984.

PAULA JUNIOR, T.J. et al. Feijão (Phaseolus vulgaris L.). In: PAULA JUNIOR, T.J.; VENZON, M. (Coord.). 101 Culturas: manual de tecnologias agrícolas. Belo Horizonte: EPAMIG, 2007. p.331-342.

PROCÓPIO, S. O. et al. Absorção e utilização do nitrogênio pelas culturas da soja e do feijão e por plantas daninhas. Planta Daninha, v.22, p.365-374, 2004.

RAMOS, L.R.M.; PITELLI, R.A. Efeitos de diferentes períodos de controle da comunidade infestante sobre a produtividade da cultura do milho. Pesquisa Agropecuária Brasileira, v.29, p.1523-1531, 1994.

RODRIGUES, L.S. et al. Divergência genética entre cultivares locais e cultivares melhoradas de feijão. Pesquisa Agropecuária Brasileira, v.37, p.78-84, 2001.

SALGADO, T.P. et al. Interferência das plantas daninhas no feijoeiro carioca. Planta Daninha, v.25, p.443-448, 2007.

SANTOS, B. M. et al. Effects of shading on the growth of nutsedges (Cyperus spp.). Weed Science, v.45, p.670-673, 1997.

SANTOS, J.B. et al. Competição entre soja resistente ao glyphosate e plantas daninhas em solo compactado. Planta Daninha, v.26, p.123-130, 2008.
SILVA, A.A. et al. Controle de plantas daninhas. Brasília - DF: ABEAS, 2000. 260p.

SOUZA, A.B. et al. Populações de plantas e níveis de adubação e calagem para o feijoeiro (Phaseolus vulgaris L.) em um solo de baixa fertilidade. Ciência e Agrotecnologia, v. 26, p. 87-98, 2002.

STONE, L.F.; SILVEIRA, P.M. Limites de competição dos componentes da produtividade de grãos da cultivar de feijoeiro-comum cv. Pérola.. Bioscience Journal, v.24, p.83-88, 2008.

TEIXEIRA, I.R. et al. Competição entre feijoeiros e plantas daninhas em função do tipo de crescimento dos cultivares. Planta Daninha, v.27, p.235-240, 2009.

VALÉRIO, C.R. ; ANDRADE, M.J.B. ; FURTADO, D.F. Comportamento das cultivares de feijão Aporé, Carioca e Pérola em diferentes populações de plantas e espaçamentos entre linhas. Ciência e Agrotecnologia, v.23, p.515-529, 1999.

WANDSCHEER, A.C.D. ; PASTORINI, L.H. Interferência alelopática de Raphanus raphanistrum L. sobre a germinação de Lactuca sativa L. e Solanum lycopersicon L.. Ciência Rural, v.38, p.949-953, 2008. 